\title{
Vitamin C twice a day enhances health
}

\author{
Alfred Roc Ordman \\ Biochemistry Program, Beloit College, Beloit, USA; Ordman@beloit.edu \\ Received 15 October 2009; revised 30 November 2009; accepted 3 December 2009.
}

\begin{abstract}
This review provides information determining how much vitamin $C$ to take, including analysis of the recent findings, which demonstrate advantages and problems with higher daily doses. The Daily Value for vitamin C was raised to $\mathbf{9 0}$ $\mathrm{mg}$ for men in 2000 , and Upper Limit of $2,000 \mathrm{mg}$ per day was established as being safe. This followed a study of urinary excretion of vitamin $C$ (AA) that demonstrated $500 \mathrm{mg}$ twice a day provides levels sufficient to cause continuous urinary excretion in humans. That is the lowest oral dosage evaluated that significantly saturates blood plasma. A later study endorsed 200 $\mathrm{mg}$ from dietary sources for the RDA. Even though plasma concentration of AA is then significantly lower, at $200 \mathrm{mg}$ daily certain white blood cells are saturated with AA. Recently many studies have indicated the benefit of high levels of AA to maintain the brain, bones, and heart, reduce damage from stroke, brain trauma, and cataracts, and lower the risk of cancer metastasis and colds. Pro-oxidant activity has been found only for i.v. adminstration, where high concentrations appear effective destroying tumor cells while not harming normal cells. This review evaluates recent research and finds it consistent with the hypothesis that people, especially older people and soldiers in combat environments, are likely to benefit if they maintain the saturating level of AA by taking $500 \mathrm{mg}$ supplements twice a day.
\end{abstract}

Keywords: Antioxidant; Vitamin C; Ascorbic Acid; Stroke; Alzheimer's; Oxidative Stress; Cardiovascular Disease; Cataracts; Osteoporosis; Mortality

\section{INTRODUCTION}

In 1956, Denham Harman, founder of AGE, proposed the free radical (ROS) theory of aging [1]. Linus Pauling proposed megadoses of the water-soluble antioxidant vitamin $\mathrm{C}$ (ascorbic acid, AA) to trap free radicals, recommending dosages up to $16 \mathrm{~g}$ per day [2]. Harman and Pauling's efforts moved the nutrition standards from levels that merely prevent short-term deficiency diseases to higher levels that reduce the risk for chronic disease associated with aging. For nutrition studies to identify risk for chronic disease, it is helpful to identify biomarkers that reflect disease-generating processes. For instance, oxidized DNA resulting from free radical damage may be a biomarker for future cancer.

\section{BACKGROUND}

Pauling based his recommendation for megadoses on the evolutionary development of an AA requirement in people. The first biomarker for long-term optimal dosage was published in 1994. King et al. [3] discovered that $500 \mathrm{mg}$ of AA taken orally every $12 \mathrm{hr}$ are sufficient to provide continuous excretion of excess AA into the urine. In 1996, a similar study by Levine M et al. [4] confirmed those results, showing that that dosage provides the highest statistically significant concentration in plasma for protection from free radical damage. But they chose a different biomarker, based on the plasma AA level necessary to saturate certain white blood cells. The choice of that biomarker led to their recommendation of only $200 \mathrm{mg} \mathrm{AA}$. That is also a level that does not require supplements for people whose food selections are rich in AA. However, neither of these studies evaluated tissue concentrations, particularly in the brain and eyes, where high levels are likely to have substantial benefits, as described below. If the higher level Pauling advocated is useful, then $500 \mathrm{mg}$ twice a day provides the highest statistically significant level possible by oral dosing.

SAFETY: There are periodic reports in the media that taking large amounts of AA over long periods of time may be harmful. A potential AA hazard was widely reported after a paper in Nature claimed that elevated AA acted as a pro-oxidant, causing DNA mutations [5]. The popular press gave much less publicity to articles reporting that that study was seriously flawed because it 
used obsolete methods [6], and that AA prevents DNA damage [7]. It had already been reported that AA prevents damage to DNA in sperm [8].

Even doses of $10 \mathrm{~g} /$ day in adults have not been reported to cause harm in confirmed scientific studies. The Food and Nutrition Board [9] of the Institute of Medicine raised the RDA for AA for men and women to 90 and $75 \mathrm{mg}$ resp., with an Upper Limit (UL) for safety established at $2 \mathrm{~g}$ per day. The UL was based on osmotic diarrhea and gastrointestinal disturbances. The Panel on dietary antioxidants and related compounds stated that the in vivo data do not clearly show a relationship between excess ascorbic acid intake and kidney stone formation, pro-oxidant effects, or excess iron absorption [10].

Another concern is that a high dose of AA distorts results of tests commonly used to measure the amount of glucose in urine and blood. Combining oral anticoagulant drugs and excessive amounts of AA can produce abnormal results in blood-clotting tests (e.g., lowering prothrombin time).

However, while media reports periodically raise concerns about taking AA and vitamin E supplements, those reports are based on misinterpretations of peer-reviewed studies. In response, a major review by numerous authorities, John N. Hathcock, Angelo Azzi, Jeffrey Blumberg, Tammy Bray, Annette Dickinson, Balz Frei, Ishwarlal Jialal, Carol S. Johnston, Frank J. Kelly, Klaus Kraemer, Lester Packer, Sampath Parthasarathy, Helmut Sies and Maret G. Traber [11], was titled "Vitamins E and $\mathrm{C}$ are safe across a broad range of intakes". They provided numerous human studies justifying the tolerable upper limit (UL) established by the Food and Nutrition Board, which is $1,000 \mathrm{mg}$ for vitamin $\mathrm{E}$ and 2,000 mg for AA.

This review describes recent studies relevant to the selection of a daily intake of AA for health maintenance.

\section{HOW CONCENTRATIONS IN DIFFERENT TISSUES AFFECT FUNCTION}

In addition to serum and white blood cell concentrations of vitamin $\mathrm{C}$, there are many other tissues in which maintaining high AA concentrations are important. Some studies below reflect the metabolic and antioxidant functions of AA in controlling cell differentiation through nutrition signaling. In a process called nutrient signaling, described only in the past decade, nutrients can transform metabolic processes as hormones do [12,13]. AA signals cell differentiation of brain and heart stem cells described below.

BRAIN: Taking $500 \mathrm{mg}$ of vitamin $\mathrm{C}$ twice daily may lessen Alzheimer's, stroke, and head trauma damage. Stroke is the leading cause of disability worldwide [14], and head trauma is common in war veterans. Several studies reveal the value of elevated levels of AA for protecting brain function. First, in humans with Alzheimer's and mild cognitive impairment, tissues and biofluids show evidence of oxidative stress [15]. Cognitive decline in aging dogs is lessened simply by adding antioxidants to the diet. The deposition of amyloid-beta is decreased [16]. A review of 300 articles by Frank and Gupta [17] concludes that the value of AA is often ambiguous, but can be recommended based upon 1) epidemiological evidence, 2) known benefits for prevention of other maladies, and 3 ) benign nature of the substance.

AA is a water-soluble antioxidant that crosses the blood-brain barrier. AA is produced in the liver of most mammals. Hibernating animals naturally store high concentrations of AA in the brain for protection from the metabolic stress that accompanies arousal [18]. In humans, brain stroke damage continues when blood flow resumes. AA substantially prevented this reperfusion injury [19]. Polidori et al. [20] show that AA is much lower in plasma for those with head trauma or intracranial hemorrhage compared to healthy subjects, while other antioxidants such as vitamin $\mathrm{E}$ are unaffected. Even at a dose of $200 \mathrm{mg} \mathrm{AA} /$ day, ischemic strokerelated lipid peroxidation decreased significantly in humans [21].

Via nutrient signaling, AA may exert effects on brain maintenance and recovery. How neural progenitor cells (NPCs) differentiate is determined by the redox state of the brain [22]. In the reducing environment produced by AA, NPCs become neurons. Under oxidizing conditions, astrocytes are formed. Prozorovski et al. [23] conclude that nontoxic manipulation of redox conditions in the brain influences NPC fate to produce neurons. People are able to generate new neurons throughout their entire lives [24]. High AA concentrations in the brain maintain the potential to generate new neurons.

HEART: The benefits of AA for the circulatory system include improved circulation and heart health. AA reverses the endothelial dysfunction caused by oxidative stress [25]. As with brain stem cells mentioned above, sufficient AA causes embryonic stem cells to differentiate into cardiac myocytes [26].

PLASMA: Heinz bodies reflect ROS damage to red blood cells (RBCs). Johnston and Cox [27] measured Heinz bodies in RBCs [28] in college students. They concluded that the antioxidant protection afforded by short-term vitamin $\mathrm{C}$ supplementation is maximal at the 500-1000 mg dosage. When taken in conjunction with 400 IU of vitamin E, a fat-soluble antioxidant, Moser et al. [29] concluded that $500 \mathrm{mg}$ of AA taken twice 
daily was superior to $200 \mathrm{mg}$ in reducing Heinz bodies, while vitamin $\mathrm{E}$ with minimal AA prevented protein carbonyl and TBARS damage.

CATARACTS: A major study in Europe shows that blood levels of AA above $49 \mu \mathrm{mol} / \mathrm{L}$ were associated with a $64 \%$ reduced odds for cataract [30]. US daily value for AA provides only about $20 \mu \mathrm{mol} / \mathrm{L}$, while 500 $\mathrm{mg}$ twice daily provides about $75 \mu \mathrm{mol} / \mathrm{L}$.

BONES: Sahni et al. [31] have shown a correlation between AA intake and $4 \mathrm{yr}$ change in bone mineral density among 334 men of mean age 75 in the Framingham Osteoporosis Study. They indicate results had only borderline significance that may relate to other factors in fruits and vegetables.

COLDS: Evidence for any benefit of AA for preventing or treating colds remains controversial. Hemilä [32] completed a meta-analysis showing that the most influential reviews contain serious inaccuracies and shortcomings, and suggests this may be a remnant of hostility to Linus Pauling's opposition to nuclear weapons. He found consistent evidence that studies using more than 1 $\mathrm{g} / \mathrm{d}$ had physiologic effects on colds. However, a later meta-analysis by Douglas and Hemilä [33] evaluated 55 comparative studies treating colds with oral doses of 200 mg of AA per day, and found at most limited evidence for any benefit in prevention or treatment of colds. The inconsistency may relate to the AA dosage. Although twice-a-day dosing is necessary to maintain elevated serum AA, I have not been able to locate any studies conducted with this protocol. Recently Saszuki et al. [34] reported that the risk of getting a cold decreased in response to single doses of AA. In a study over the range from 50 to $500 \mathrm{mg}$ AA daily, the risk of contracting three or more colds during a 5 yr period was decreased $66 \%$ by daily intake of $500 \mathrm{mg}$.

CANCER: Research has demonstrated that mutations of mitochondria accumulate with age [35]. Each mitochondrion generates about 4,000 free radicals per second [36,37]. In human tumors, mitochondrial DNA mutations occur at high frequency. Ishikawa et al. [38] demonstrated that pretreatment of tumor cells in mice with free radical scavengers prevents those cells from metastasizing. By prevention of mitochondrial DNA mutations, a mechanism to maintain a high concentration of antioxidants in mitochondria could reduce the risk of metastatic tumors.

But at higher plasma levels achieved by intravenous (iv) doses, AA becomes a pro-oxidant that may be toxic to cancer cells. In vitro AA killed cancer cells at extracellular concentrations above $1 \mathrm{mM}$ [39]. Chen et al. [40] found pharmacologic concentrations of AA caused prooxidant cytotoxicity toward a variety of tumor cells in vitro, without adversely affecting normal cells. Ovar- ian, pancreatic, and glioblastoma tumors established in mice significantly decreased growth rates in vivo in response to parenteral AA administration.

Padayatty et al. [41] demonstrate using hospital volunteers that this concentration can be achieved in vivo, reaching $13 \mathrm{mM}$ for a 50-g iv dose, 140-fold greater than can be achieved by oral dosing. A review by Frei and Lawson [6] also shows many recent studies demonstrating that millimolar AA by iv infusion will kill cancer cells but not normal cells.

DEATH: Despite the evidence for mechanisms by which AA may benefit, there remains doubt about the benefits of antioxidants in general. A review in JAMA in 2007 by Bjelakovic et al. [42] reviewed all randomized trials of adults taking antioxidants for the prevention of several diseases, finally including 68 randomized trials with 232,606 participants. They found beta-carotene, vitamin A and vitamin E significantly increased mortality. Vitamin C had no significant effect on mortality.

DISCUSSION: One goal for a review is to elucidate pros and cons. However, except for the flawed Podmore study, I have found no reason for not taking $500 \mathrm{mg}$ of AA twice a day except inconvenience. Since the UL was established at $2 \mathrm{~g} / \mathrm{d}$, studies have at most questioned the benefit of AA supplements, and have often demonstrated both theoretical and practical benefit.

Physicians accept the role of AA as a vitamin for immediate health benefits such as prevention of scurvy. Ever since Harman's free radical theory of aging and anti-nuclear activist Linus Pauling's proposal to take megadoses of AA as an ROS scavenger to maintain long-term health, people have found higher doses controversial. The American Aging Association held a consensus conference in 1996 that concluded a daily dose from 200 to $1,000 \mathrm{mg}$ per day in divided doses was warranted [43].

The dosages still advocated actively in the literature are three. They are: $90 \mathrm{mg}$, found in most diets, providing the Daily Value, sufficient to prevent scurvy; $200 \mathrm{mg}$, the highest intake likely through a conscientious diet, sufficient to saturate certain WBCs, but substantially lower than was found necessary in many studies cited in Table 1, and $500 \mathrm{mg}$ twice a day, which can be obtained only through oral supplements, the highest dosage necessary and sufficient for oral dosage saturation of plasma in vivo.

Given the safety of AA supplements, greater education might help people to alleviate the expense and suffering that may be caused by inadequate AA intake. However, the media report erroneous findings, like those of Podmore et al. [5] that AA may cause DNA mutations, while they fail to report the UL for safe consumption of AA. 
Table 1. Summary of potential damage by oxidative stress and benefits of aa intakes of $500 \mathrm{mg}$ twice a day to humans.

\begin{tabular}{ll}
\hline & ROS contribute to Alzheimer's [15] \\
BRAIN & AA reduces cognitive decline [16] \\
& AA reduces reperfusion injury [19] \\
& AA reduces damage from head trauma [20] \\
& AA generates new neurons [23] \\
\hline \multirow{3}{*}{ HEART } & AA reverses endothelial dysfunction [25] \\
& AA generates new cardiac myocytes [26] \\
& AA (500 mg twice daily) protects plasma [29] \\
EYES & AA reduced cataract odds 64\% [30] \\
COLDS & AA (500 mg) reduced frequency of colds by \\
& 66\% [34] \\
BONES & Highest tertile had less bone loss [31] \\
& AA reduced mutations causing metastases \\
CANCER & [38] \\
& iv AA reduced tumor growth in mice and did \\
not harm normal cells in vitro [40]
\end{tabular}

\section{CONCLUSIONS}

As documented above, $500 \mathrm{mg}$ of vitamin $\mathrm{C}$ taken every $12 \mathrm{hrs}$ may reduce many major causes of chronic disease and aging decline, not to mention colds. The safety and benefit of vitamin $C$ supplements is of critical importance, especially for those in war zones at risk for brain trauma or of advancing years at risk for chronic disease and stroke. People ought to be informed of the safety and benefit of vitamin $\mathrm{C}$ supplements.

\section{REFERENCES}

[1] Beckman, K.B. and Ames, B.N. (1998b) The free radical theory of aging matures. Physiological Reviews, 78(2), 547-581.

[2] Pauling, L. (1970) Vitamin C the common cold. W. H. Freeman, San Francisco.

[3] King, G., Beins, M., Larkin, J., Summers, B. and Ordman, A.B. (1994) Rate of excretion of vitamin $\mathrm{C}$ in human urine. $A G E, \mathbf{1 7 ( 1 )}, 87-92$.

[4] Levine, M., Conry-Cantilena, C., Wang, Y., Welch, R.W. and Cantilena, L.R. (1996) Vitamin C pharmacokinetics in healthy volunteers: Evidence for a recommended dietary allowance. Proceedings of the National Academy of Sciences of the United States of America, 93(8), 37043709.

[5] Podmore, I.D., Griffiths, H.R., Herbert, K.E., Mistry, N., Mistry, P. and Lunec, J. (1998) Vitamin C exhibits prooxidant properties. Nature, 392(6676), 559.

[6] Frei, B. and Lawson, S. (2008) Vitamin C and cancer revisited. Proceedings of the National Academy of Sciences of the United States of America, 105(32), 11037-
11038 .

[7] Helbock, H.J., Beckman, K.B., Shigenaga, M.K., Walter, P., Woodall, A.A., Yeo, H.C. and Ames, B.N. (1998) DNA oxidation matters: The HPLC-EC assay of 8-oxodeoxyguanosine and 8-oxo-guanine. Proceedings of the National Academy of Sciences of the United States of America, 95(1), 288-293.

[8] Park, E.M., Shigenaga, M.K., Degan, P., Korn, T.S., Kitzler, J.W., Wehr, C.M., Kolachana, P. and Ames, B.N. (1992) Assay of excised oxidative DNA lesions: Isolation of 8-oxoguanine and its nucleoside derivatives from biological fluids with a monoclonal antibody column. Proceedings of the National Academy of Sciences of the United States of America, 89(8), 3375-3379.

[9] Food and Nutrition Board (2000) Dietary reference intakes for vitamin $\mathrm{C}$, vitamin $\mathrm{E}$, selenium and carotenoids. National Academy of Sciences.

[10] Naidu, K.A. (2003) Vitamin C in human health and disease is still a mystery? An overview. Journal of Nutrition, 2(7), 7-23.

[11] Hathcock, J.N., Azzi, A., Blumberg, J., Bray, T., Dickinson, A., Frei, B., Jialal, I., Johnston, C.S., Kelly, F.J., Kraemer, K., Packer, L., Parthasarathy, S., Sies, H., Traber, M.J. (2005) Vitamins E and C are safe across a broad range of intakes. American Journal of Clinical Nutrition, 81(4), 736-745.

[12] Bhalla, U.S. and Iyengar, R. (1999) Emergent properties of networks of biological signaling pathways. Science, 283(5400), 381-387.

[13] Ordman, A.B. (2008) Pilot study for an age and gender-based nutrient signaling system for weight control. $A G E, \mathbf{3 0}(2), 201-208$.

[14] Zweifler, R.M. (2003) Management of acute stroke. Southern Medical Journal, 96(4), 380-385.

[15] Su, H., Gornitsky, M., Geng, G., Velly, A.M., Chertkow, H. and Schipper, H.M. (2008) Diurnal variations in salivary protein carbonyl levels in normal and cognitively impaired human subjects. $A G E, \mathbf{3 0}(\mathbf{1}), 1-9$.

[16] Araujo, J.A., Studzinski, C.M., Head, E., Cotman, C.W. and Milgram, N.W. (2005) Assessment of nutritional interventions for modification of age-associated cognitive decline using a canine model of human aging. $A G E$, 27(1), 27-37.

[17] Frank, B. and Gupta, S. (2005) A review of antioxidants and Alzheimer's disease. Annals of Clinical Psychiatry, 17(4), 269-286.

[18] Tøien, O., Drew, K.L., Chao, M.L. and Rice, M.E. (2001) Ascorbate dynamics and oxygen consumption during arousal from hibernation in Arctic ground squirrels. American Journal of Physiology-Regulatory, Integrative and Comparative Physiology, 281(2), R572-R583.

[19] Rozell, N. (1998) Of ground squirrels, Vitamin C and stroke. Alaska Science Forum Article, \#1378.

[20] Polidori, M.C., Mecocci, P. and Frei, B. (2001) Plasma vitamin $\mathrm{C}$ levels are decreased and correlated with brain damage in patients with intracranial hemorrhage or head trauma. Stroke, 32(4), 898-902.

[21] Polidori, M.C., Pratic, D., Ingegni, T., Mariani, E., Spazzafumo, L., Del Sindaco, P., Cecchetti, R., Yao, Y., Ricci, S., Cherubini, A., Stahl, W., Sies, H., Senin, U. and Mecocci, P. (2005) Effects of vitamin $\mathrm{C}$ and aspirin in 
ischemic stroke-related lipid peroxidation: Results of the AVASAS Study. BioFactors, 24(1-4), 265-274.

[22] Adler, E.M. (2008) Science signaling: Sirtuin to become astrocytes. Science, 320(5874), 291.

[23] Prozorovski, T., Schulze-Topphoff, U., Glumm, R., Baumgart, J., Schröter, F., Ninnemann, O., Siegert, E., Bendix, I., Brüstle, O., Nitsch, R., Zipp, F. and Aktas, O. (2008) Sirt1 contributes critically to the redox-dependent fate of neural progenitors. Nature Cell Biology, 10(4), 385-394.

[24] Song, H., Kempermann, G., Wadiche, L. O., Zhao, C., Schinder, A.F., Bischofberger, J. (2005) New neurons in the adult mammalian brain: Synaptogenesis and functional integration. The Journal of Neuroscience, 25(45), 10366-10368.

[25] Levine, G.N., Frei, B., Koulouris, S.N., Gerhard, M.D., Keaney, J.F. and Vita, J.A. (1996) Ascorbic acid reverses endothelial vasomotor dysfunction in patients with coronary artery disease. Circulation, 93(87), 1107-1113.

[26] Takahashi, T., Lord, B., Schulze, P.C., Fryer, R.M., Sarang, S.S., Gullans, S.R. and Lee, R.T. (2003) Ascorbic acid enhances differentiation of embryonic stem cells into cardiac myocytes. Circulation, 107(3), 1912-1916.

[27] Johnston, C.S. and Cox, S.K. (2001) Plasma-saturating intakes of vitamin $\mathrm{C}$ confer maximal antioxidant protection to plasma. American Journal of Clinical Nutrition, 20(6), 623-627.

[28] Beutler, E., Lichtman, M.A., Coller, B.S. and Kipp, T.J. (1995) Williams hematology. 5th Edition, McGraw-Hill, New York, L26.

[29] Moser, L.R. and Ordman, A.B. (2006) Design for a study to determine optimal dosage of ascorbic acid and alphatocopherol in humans. $A G E, \mathbf{2 8 ( 1 )}, 77-84$.

[30] Valero, M.P., Fletcher, A.E., De Stavola, B.L., Vioque, J. and Alepuz, V.C. (2002) Vitamin C is associated with reduced risk of cataract in a Mediterranean population. Journal of Nutrition, 132(6), 1299-1306.

[31] Sahni, S., Hannan, M.T., Gagnon, D., Blumberg, J., Cupples, L.A., Kiel, D.P. and Tucker, K.L. (2008) High vitamin $\mathrm{C}$ intake is associated with lower 4-year bone loss in elderly men. Journal of Nutrition, 138(10), 1931-1938.

[32] Hemilä, H. (1996) Vitamin C supplementation and common cold symptoms: Problems with inaccurate reviews. Nutrition, 12(11), 804-809.

[33] Douglas, R.M. and Hemilä, H. (2005) Vitamin C for preventing and treating the common cold. PLoS Medicine, 2(6), e168.

[34] Sasazuki, S., Sasaki, S., Tsubono, Y., Okubo, S., Hayashi, M. and Tsugane, S. (2006) Effect of vitamin C on common cold: Randomized controlled trial. European Journal of Clinical Nutrition, 60(1), 9-17.

[35] Beckman, K.B. and Ames, B.N. (1998a) Mitochondrial aging: Open questions. Annals of the New York Academy of Sciences, 854, 118-127.

[36] Gredilla, R., Sanz, A., Lopez-Torres, M. and Barja, G. (2001) Caloric restriction decreases mitochondrial free radical generation at complex I and lowers oxidative damage to mitochondrial DNA in the rat heart. The Federation of American Societies for Experimental Biology Journal, 15(9), 1589-1591.

[37] Myers, M.W. and Bosmann, H.B. (1974) Mitochondria! Protein content and enzyme activity of reuber hepatoma H-351. Cancer Research, 34(8), 1989-1994.

[38] Ishikawa, K., Takenaga, K., Akimoto, M., Koshikawa, N., Yamaguchi, A., Imanishi, H., Nakada, K., Honma, Y. and Hayashi, J. (2008) ROS-generating mitochondrial DNA mutations can regulate tumor cell metastasis. Science, 320(5876), 661-664.

[39] Sakagami, H., Satoh, K., Hakeda, Y. and Kumegawa, M. (2000) Apoptosis-inducing activity of vitamin C and vitamin K. Cell and Molecular Biology, 46(1), 129-143.

[40] Chen, Q., Espey, M.G., Sun, A.Y., Pooput, C., Kirk, K.L., Krishna, M.C., Khosh, D.B., Drisko, J. and Levine, M. (2008) Pharmacologic doses of ascorbate act as a prooxidant and decrease growth of aggressive tumor xenografts. Proceedings of the National Academy of Sciences of the United States of America, 105(32), 11037-11038.

[41] Padayatty, S.J., Sun, H., Wang, Y., Riordan, H.D., Hewitt, S.M., Katz, A., Wesley, R.A. and Levine, M. (2004) Vitamin $\mathrm{C}$ pharmacokinetics: Implications for oral and intravenous Use. Annals of Internal Medicine, 140(7), 533537.

[42] Bjelakovic, G., Nikolova, D., Gluud, L.L., Simonetti, R. G. and Gluud, C. (2007) Mortality in randomized trials of antioxidant supplements for primary and secondary prevention. Journal of the American Medical Association, 297(8), 842-857.

[43] Ordman, A.B. (1999) Background for a consensus on the value of consuming vitamin $\mathrm{C}$ and $\mathrm{E}$ supplements. $A G E$, 22(1), 127. 